\title{
Australian quasigeoid modelling: Review, current status and future plans
}

\author{
Jack C. McCubbine ${ }^{1, *}$, Will E. Featherstone ${ }^{2}$, and Nicholas J. Brown ${ }^{1}$ \\ ${ }^{I}$ National Geodesy Section, Place, Space and Communities Division, Geoscience Australia, Canberra, Australia \\ ${ }^{2}$ School of Earth and Planetary Sciences, Curtin University of Technology, Perth, Australia
}

\section{Article history:}

Received 26 May 2021

Revised 6 July 2021

Accepted 10 August 2021

Keywords:

Australia, Quasigeoid, Geoid, Gravity

Citation:

McCubbine, J. C., W. E. Featherstone, and N. J. Brown, 2021: Australian quasigeoid modelling: Review, current status and future plans. Terr. Atmos. Ocean. Sci., 32, 829-845, doi: 10.3319/TAO.2021.08.10.01

\begin{abstract}
We provide a historical review and critique of regional geoid and quasigeoid modelling over the Australian continent, covering the earliest models from the late 1960s through to the present day and beyond. The most recently released official model for GPS/GNSS surveyors, AUSGeoid2020, was specifically calculated to enable them to determine Australian Height Datum heights from Geocentric Datum of Australia 2020 ellipsoidal heights in a more direct manner without the need for postsurveying adjustments. We summarise the deficiencies in the Australian Height Datum and how they are now being addressed by a proposed new vertical height system that is underpinned by a gravimetric-only quasigeoid model. We also summarise the results of some experiments that we have conducted to explore potential refinements that could be made to our computational processes, and future plans to acquire gravity data in the problematic coastal zones using airborne methods.
\end{abstract}

\section{REVIEW AND SUMMARY OF AUSTRALIAN GEOID AND QUASIGEOID MODELS}

\subsection{Historical Aspects}

Various regional models of the geoid - or more recently the quasigeoid - have been available for the Australian continental landmass since 1967. These models were historically used to reduce geodetic surveying measurements to the non-geocentric Australian National Spheroid (ANS). Summarising from Kearsley and Govind $(1991,1992)$, the first geoid-ANS separation model, published by Fischer and Slutsky (1967), was computed from 600 astrogeodetic deflection observations, reasonably evenly distributed across the Australian mainland. These deflection data were interpolated onto a $1^{\circ}$ by $1^{\circ}$ grid and transformed into a model of the geoid using the technique of astrogeodetic levelling (e.g., Heiskanen and Moritz 1967). This first model was arbitrarily fixed to zero at the Johnston Origin pillar in central Australia. Four years later, Fryer $(1971,1972)$ produced a refined version of this astrogeodetic geoid model, including additional deflections, gridded at $0.5^{\circ}$ by $0.5^{\circ}$, and fixed the geoid-ANS separation to $-6 \mathrm{~m}$ at the Johnston Origin, which better aligned it with mean sea level (MSL) at the coasts.

\footnotetext{
* Corresponding author

E-mail: jack.mccubbine@ga.gov.au
}

These models of geoid undulations were both referenced to the ANS, which has semi-major axis $a=6378160 \mathrm{~m}$ and inverse flattening $1 / f=298.25$ (exact)' but is not geocentric (cf. Mather 1971).

These are the only regional Australian geoid models to have been computed exclusively from astrogeodetic deflections. However, the use of vertical deflections has not become totally obsolete. In recent years, a few tens of new and more precise vertical deflections have been collected using contemporary digital equipment (CCD star cameras integrated with GPS) and used to assess gravimetric-only quasigeoid models in Perth, Western Australia, where the quasigeoid gradient is very steep (Schack et al. 2018). The historical vertical deflection data, used by Fischer-Slutksy and Fryer, are also still of some relevance. They have been used to evaluate geoid and quasigeoid models determined entirely from gravity data (e.g., Featherstone and Morgan 2007; Featherstone et al. 2018a) and experiments have been conducted into the a posteriori fitting of a gravimetric-only geoid model to these historical vertical deflections (Featherstone and Lichti 2009). The estimated accuracy of these historic vertical deflections is variable and not available on a per-station basis, with estimates by different authors ranging from \pm 0.22 arc-sec to \pm 0.76 arc-sec, which are cited in Featherstone et al. (2018a). 
In 1971, the Australian Height Datum (AHD, Roelse et al. 1971) was realised as the first and only vertical datum for the Australian mainland from a least squares adjustment of a continent-wide set of differential levelling observations, constrained to zero height at 30 tide gauge observations of mean sea level distributed around the coast. In 1983, differential levelling in Tasmania was least squares adjusted by holding two tide gauges fixed. Though technically two separate vertical datums, both are called AHD. Several attempts have been made to unify the AHD between the Australian mainland and Tasmania (Rizos et al. 1991; Featherstone 2000b; Filmer and Featherstone 2012a), but none of these have led to a revision of AHD heights in Tasmania or the mainland. Gravity observations were not collected along all the levelling traverses at that time, so GRS67 normal gravity was used instead via truncated versions of the equations in Rapp (1961) (Roelse et al. 1971). This provided a normal-orthometric height (cf. Featherstone and Kuhn 2006) of $H=566.3 \mathrm{~m}$ at the Johnston Origin, which was coupled with the ANS ellipsoidal height of $H=571.2 \mathrm{~m}$ (legally fixed at that time) to provide a new reference value for the geoid at the Johnston Origin of $+4.9 \mathrm{~m}$. This was subsequently used to re-align Fryer's astrogeodetic geoid model with a shift of $+10.9 \mathrm{~m}$

At around the same time, Mather (1969) produced a gravimetric co-geoid model which, unlike the models produced by Fischer-Slutsky and Fryer, was referenced to the geocentric GRS67 ellipsoid. Rather than using astrogeodetic deflections, Mather used free-air gravity anomalies determined from a nation-wide set of gravity observations that had been collected primarily for resource exploration (Fraser et al. 1976; cf. Gilliland 1987). A remove-computerestore technique was employed using a combined global geopotential model, determined from both satellite and terrestrial gravity data. Residual free air gravity anomalies were then transformed in to geoid undulations using Stokes's integration with an unmodified kernel. After a translation for the geocentre between the ANS and GRS67 (Mather 1971), Mather's model was compared to Fischer-Slutsky's model and showed differences exceeded $10 \mathrm{~m}$ and had an RMS of $\pm 3 \mathrm{~m}$ (Kearsley and Govind 1992). The differences between the models were attributed to inadequacies (long wavelength control and gravity data density) in the gravity data used by Mather and the limited number of vertical deflections used by Fischer-Slutsky (Kearsley and Govind 1992). Mather's model was technically a free-air co-geoid because direct and indirect topographic effects (e.g., Heiskanen and Moritz 1967) were not considered.

Shortly after, Grushinsky et al. (1971) produced a gravimetric quasigeoid model by evaluating Stokes integral, using direct numerical integration, in a remove compute restore scheme. As this work was done in Russia, where the Molodensky theory was prevalent, the gravity anomaly data used in the computation were a zero order approximation to the Molodensky gravity anomaly (free air anomalies) computed from gridded Bouguer gravity anomalies (supplied by the Bureau of Mineral Resources) and a topographic map of Australia. They estimated the accuracy of the gridded free air gravity anomalies to be between 5 and $10 \mathrm{mGal}$. Their model was (1) compared to that produced by Mather (1969) which they report had differences with an RMS of $\pm 5 \mathrm{~m}$ and (2) the astrogeodetic model by Fischer and Slutsky (1967) - and they report differences with an RMS $\pm 3.7 \mathrm{~m}$ at a 51 points.

In the mid-to-late-1980s, Global Positioning System (GPS) technology started to become prevalent for geodetic surveying through the use of carrier-phase measurements, something that GPS was never designed to do. Therefore, in contrast to the earlier need for a regional model of the geoid with respect to the ANS, the GPS user community needed a model to determine physically meaningful heights from GPS-derived ellipsoidal heights that refer to a geocentric ellipsoid, nominally WGS84. In recognition of this, academics at the University of New South Wales and the University of South Australia independently computed gravimetric co-geoid models. Co-geoid models were produced by $\mathrm{Ke}-$ arsley $(1988 \mathrm{a}, \mathrm{b})$ using the 1980 release of the Australian Geological Survey Organisation's national gravity database, which comprised $\sim 360000$ terrestrial gravity measurements the Australian mainland and 75000 measurements offshore. This and subsequent co-geoid models used "ring integration" (Kearsley 1985, 1986; Kearsley et al. 1998) to evaluate Stokes's integral where the integration radius from the computation point was limited to 0.5 degrees and with an unmodified kernel. Kirby et al. (1997) showed that the ring integration approach gives results commensurate with quadrature integration of rectangular blocks. Gilliland (1989) used same release of the gravity database to calculate the free air anomalies on a $0.1^{\circ}$ by $0.1^{\circ}$ grid. The Kearsley and Gilliand models employed a remove-compute-restore technique. Residual free air gravity anomalies were then transformed to residual geoid heights on a $1^{\circ}$ by $1^{\circ}$ grid using Stokes's integration, evaluated by direct numerical integration over $3^{\circ}$ by $3^{\circ}$ blocks, with an unmodified kernel. Compared to Mather's model, Gilliland's model had significant differences, including a large N/S trend, which were attributed to the improved gravity data quality and coverage (Kearsley and Govind 1992). Both Kearsley's and Gilliland's models were also free-air co-geoids.

In 1991, the then Australian Surveying and Land Information Group (AUSLIG) formally recognised the need for a national geocentric gravimetric geoid model for use in conjunction with GPS. They subsequently used a gravimetric geoid model called AUSGeoid91 (Kearsley and Govind 1992). This model was referenced to the WGS84 ellipsoid and was again computed with the 1980 release of the national gravity database using an unmodified Stokes integral (evaluated by brute-force numerical ring integration) with the remove-compute-restore technique. For this calculation, 
global model OSU89A (Rapp and Pavlis 1990) was used which contained spherical harmonic coefficients up to degree and order 360 and the integration was performed within a 0.5 degree radius about each computation point - this was so that the terrestrial gravity data only contributed to wavelengths shorter than those in the global model. Two years later, AUSGeoid91 was superseded by AUSGeoid93 (Kearsley and Steed 1995), which was computed using the same computational technique but with a refined global model OSU91A to 360 (Rapp et al. 1991). AUSGeoid93 was then used as the national standard for converting GPS measurements to AHD heights for the following five years (Stead and Holtznagel 1994). AUSGeoid91 and AUSGeoid93 were also free-air co-geoids.

Throughout the mid-1990s and early 2000s, a number of experimental studies were undertaken around refining the computational techniques in the Australian setting. In a Ph.D. thesis, Zhang (1997) looked at the merits of evaluating Stokes's integral in the Fourier domain. Featherstone and Kirby (2000) detailed a method to utilise a digital elevation model to reduce spatial aliasing when interpolating pointwise gravity anomalies onto a regular grid. Various gridding/interpolation methods and their impact on geoid computations was assessed by Goos et al. (2003) and Zhang and Featherstone (2004). Some local geoid models were also produced for example by Freund et al. (1997) just for the Australian Capital Territory, a series of geoid models over Western Australia were produced by Featherstone (1999) to explore the impact of modifying Stokes kernel, and Vella and Featherstone (1999) computed a quasigeoid over Tasmania using a modified Stokes kernel with the 1D discrete Fourier technique (Haagmans et al. 1993). Alternative computation methods were also experimented with, particularly in the Perth region. Claessens et al. (2001) investigated point mass modelling of the geoid, but the results were contaminated by erroneous marine gravity data (cf. Featherstone 2009). Darbeheshti and Featherstone (2009, 2010) investigated non-stationary least squares collocation (LSC), borrowing from spatial statistics to form covariance functions in a region where the gravity field is not a stationary stochastic variable. Soltanpour et al. (2006) investigated non-orthogonal second generation wavelets as an alternative to LSC for creating a hybrid geoid by combining gravimetric and geometric geoid models. However, none of these local models were formally released or officially adopted in the AUSGeoid models, but the investigations informed the computation processes.

\subsection{Contemporary Quasigeoid Modelling}

In 1998, AUSLIG in collaboration with academic sector computed a new geoid model, AUSGeoid98 (Featherstone et al. 2001). It also brought together the three most prominent gravimetric geoid modellers in Australia at that time: Kearsley, Gilliland, and Featherstone, who jointly attracted funding from the Australian Research Council (ARC) for the project. The methods were provided, free-of-charge, to AUSLIG who ran the final computations and released and administered the model. This practice has continued ever since, and allows a single point of contact for the model(s). Compared to previous Australian geoid models, the computation of AUSGeoid98 was (1) more theoretically rigorous, (2) contained substantially more gravity data, gridded at a comparatively higher resolution, and (3) used the 1D Fourier method to evaluate Stokes's integral in conjunction with a deterministically modified kernel (Featherstone et al. 1998) and parameters specifically chosen to fit GPS-levelling ground truth data. Moreover, it included gravimetric terrain corrections and their indirect effects, so was a geoid and not a co-geoid. AUSGeoid98 geoid undulations were specifically referenced to the GRS80 ellipsoid (Moritz 1980) to be directly compatible with the Geocentric Datum of Australia 1994 (GDA94; Featherstone 1994) and also GPS.

(1) Prior to AUSGeoid98, previous Australian geoid models had been computed by evaluating Stokes's Integral with free air gravity anomalies only. This approach does not properly account for the effect of topographic masses external to the geoid (Heiskanen and Moritz 1967). For AUSGeoid98, topographic effects were accounted for more precisely by first adding terrain corrections to the free air anomalies (Kirby and Featherstone 1999, 2001) evaluating Stokes integral and then applying the primary indirect effect given by the quadratic term of Wichiencharoen's (1982) formula, to produce the final geoid model.

(2) Onshore, over 690000 terrestrial gravity observations (from the 1996 release of the national gravity database) were reduced to Faye gravity anomalies (Heiskanen and Moritz 1967) and combined with, 134539 shipborne gravity data and satellite altimetry-derived gravity anomalies offshore and gridded on a 2 by 2 arc-minute grid using tensioned splines (Smith and Wessel 1990). This gravity anomaly grid was then used in a remove-compute-restore scheme to compute the residual geoid undulations with full 360 degree and order spherical harmonic expansion of the Earth Gravity Model 1996 (EGM96; Lemoine et al. 1998) acting as the reference model.

(3) Stokes's integral is a convolution integral used to transform gravity anomalies $(\Delta g)$ into geoid undulations or $N$-values [Eq. (1)]. Prior to AUSGeoid98, Australian geoid models computed from gravity data evaluated Stokes's integral by brute-force numerical integration using an unmodified Stokes kernel $[S(\Psi)]$. For AUSGeoid98, the convolution integral was evaluated in the Fourier domain, where the convolution of two functions (the gravity anomaly and modified Stokes's kernel) becomes their pointwise products - which is substantially more efficient to evaluate (Haagmans et al. 1993; Zhang 
1997). To further reduce the computational load, and to accommodate the latitude dependency of the computation point in spherical distance $(\Psi) /$ Stokes's kernel, the two dimensional convolution was evaluated as the sum of one dimensional convolutions [Eq. (2)].

In addition to this, the geoid undulations were partially high-pass filtered by only evaluating the integral over a restricted radius from the computation point $(\sigma<\widehat{\sigma})$ and by adapting Stokes's kernel to produce the modified kernel, $\widehat{S}(\Psi)$ described by Featherstone et al. (1998). Vaníček and Featherstone (1998) discuss the partial filtering properties of limited integration caps and deterministically modified kernels. A range of geoid models were produced using a number of capped integration radii $(\widehat{\sigma})$ with the modification degree set to $\mathrm{M}=20$. The intention of the (partial) high pass filtering was to alleviate the contribution of any longwavelength errors present in the national gravity database.

$N=\kappa \int_{\sigma} \Delta g S(\Psi) d \sigma$

$N\left(\phi_{i}\right)=\kappa \sum_{j} \Delta g\left(\phi_{j}\right) \circledast \widehat{S}\left(\Psi_{i, j}\right) d \sigma$

The range of potential AUSGeoid98 models were finally compared to a dataset of 900 geometric geoid undulations calculated from differentially levelled AHD heights $H$ and GPS derived ellipsoidal heights $h$. The comparison was used to identify the optimal choice of integration cap radii and to gauge the precision of the geoid model for its intended main use in GPS-levelling. With an RMS in the GPSlevelling/geoid differences of $\pm 0.364 \mathrm{~m}$, the integration cap radius was determined to be $1^{\circ}$. To align the AUSgeoid98 model with the AHD a zero-degree term was determined from the $93.7 \mathrm{~cm}$ mean of the GPS-levelling/geoid differences and subtracted from the model, which also absorbs any constant offset between the AHD and the geoid.

Whilst AUSGeoid98 was a substantial improvement over its predecessors, the $\pm 0.364 \mathrm{~m}$ RMS of the comparison of the model to GPS minus AHD heights was much larger than its international counterparts (Featherstone et al. 2001). The differences were determined to be largely attributable to the discrepancies in the way AHD was realised (e.g., Kearsley et al. 1988; Morgan 1992; Featherstone and Stewart 1998; Featherstone and Filmer 2008; Filmer and Featherstone 2009). One prominent feature of the differences was a large N/S tilt (Featherstone 2004, 2006), which was identified as being due to mean sea surface topography (aka the ocean's time-mean dynamic topography) embedded in AHD due to referencing the levelling observations to 30 estimates of mean sea level (Featherstone and Filmer 2012) around the Australian mainland. There also a number of local distortions (>150 mm) present in the levelling network, which is to be anticipated when differential levelling is conducted over a vast area such as mainland Australia to third order tolerances (12 root $\mathrm{k}$ ).

The primary intention of the AUSGeoid98 model was to enable GPS users to determine AHD heights, but due to the significant differences this was not possible to an acceptable degree of accuracy for most uses (Featherstone 1998, 2008). Incorporating the difference between the AHD reference level and the geoid model, by interpolating the GPS-AHD and geoid differences onto a grid and including this as second "layer" to the model, has been proposed in a number of studies (e.g., Featherstone 1998, 2000a; Featherstone and Sproule 2006). It was formally implemented in 2009 with the computation of a new, hybrid quasigeoid model, AUSGeoid09. AUSGeoid09 was computed in two stages (Brown et al. 2011; Featherstone et al. 2011). Before this nationwide implementation of hybrid models, a small hybrid patch in Perth, Western Australia, had been applied to the released version of AUSGeoid9 8 because of the steep geoid gradients in this area (Featherstone 2000a).

First, a gravimetric quasigeoid model was computed, following an almost identical computational strategy as AUSGeoid98, using the latest release of the Australian gravity database ( 1.4 million measurements), more up-to-date altimetry derived gravity anomalies - without including the shipborne data (Featherstone 2009), and using EGM2008 to degree 2160 (Pavlis et al. 2012, 2013) as the reference model in the remove-compute-restore process. The gravity data were gridded at 1 by 1 arc minute and a range of geoid models were computed by varying the integration cap radius and, this time, also the Stokes kernel modification degree. The optimal parameters were determined to be an integration cap of 1 degree and modification degree of $\mathrm{M}$ $=40$. Importantly, the primary indirect effect was not included in the computation so as to compute a "quasi"geoid model (Molodensky et al. 1960, 1962; Moritz 1968; Featherstone and Kirby 1998), which is more consistent with the normal-orthometric height system adopted for the AHD (Featherstone and Kuhn 2006; Filmer et al. 2010; Filmer and Featherstone 2012b).

A second layer was then added to the gravimetric quasigeoid model which captured the differences between the "gravimetric-only" quasigeoid model and GPS-derived GDA94 (ICSM 1996) ellipsoidal heights minus AHD levelled heights. This layer was calculated by gridding the difference using least squares collocation, after removing and then subsequently restoring a tilted plane that was predominantly north-south because of the tilt in the AHD (Featherstone and Filmer 2012). After the inclusion of this additional layer, the standard deviation of the ellipsoidal - AHD heights and quasigeoid differences dropped from \pm 222 to $\pm 30 \mathrm{~mm}$. AUSGeoid09 was then used as the national standard for converting GPS measurements to AHD heights for the following seven years.

AUSGeoid2020 (Fig. 1a) is the most recently 

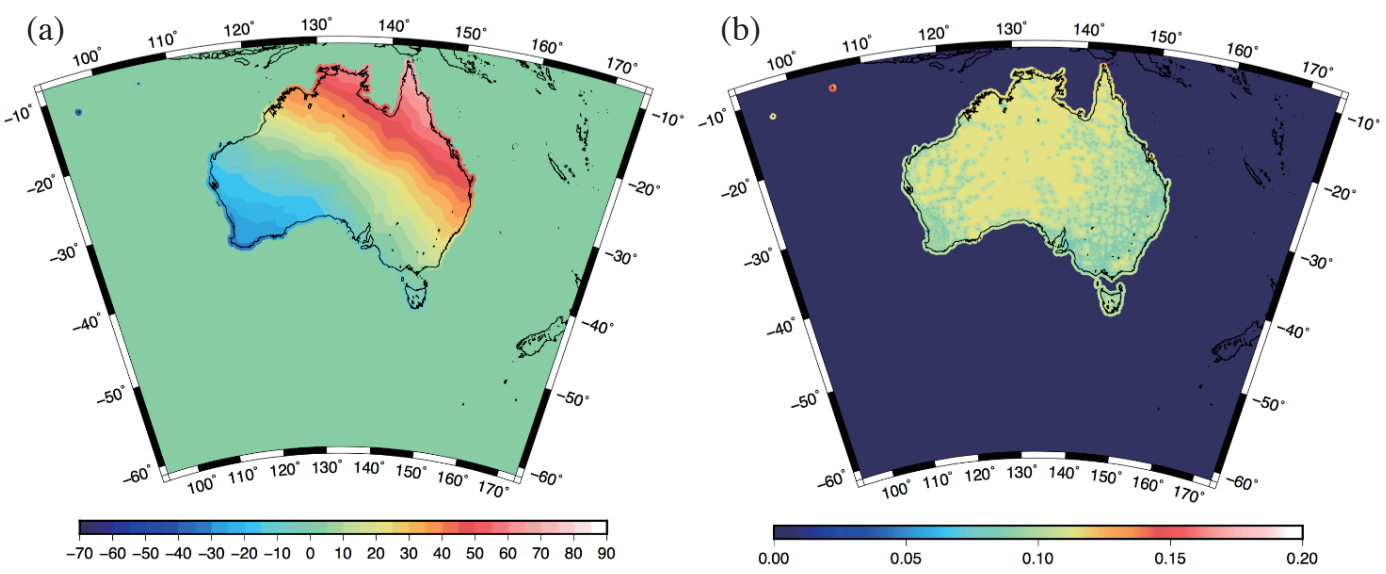

Fig. 1. (a) The AUSGeoid2020 model separation from the GRS80 ellipsoid, the scale bar is in metres. (b) The propagated uncertainty in the AUSGeoid2020 model, the scale bar is in metres.

computed model used for calculating AHD heights from ellipsoidal heights (Brown et al. 2018; Featherstone et al. 2018b). AUSGeoid2020 was computed in 2016, and similar to AUSGeoid09 it is a "hybrid" model. The underlying gravimetric component, the Australian Gravimetric Quasigeoid 2017 (AGQG2017, section 3) was computed using an identical scheme as used for AUSGeoid09. 1.8 million measurements from the 2016 release of the national gravity data base were combined with version 23.1 of the Sandwell et al. $(2013,2014)$ altimetry derived gravity anomalies and terrain corrections determined from a 1 arc second digital elevation model (McCubbine et al. 2017) to produce a Faye gravity anomalies on a 1 arc minute grid.

Using EGM2008 to degree 2160 as the reference in the remove-compute-restore scheme, Stokes's integral was then evaluated with the Featherstone et al. (1998) modified Stokes kernel and a range of modification degrees and integration cap radii. The parameters were found to be an integration cap radius of 0.5 degrees and a modification degree of $M=40$. The standard deviation of the differences between the gravimetric-only quasigeoid model and a dataset of 7224 ellipsoidal minus AHD heights was \pm 186 $\mathrm{mm}$. Apart from using later releases of gravity and terrain datasets, AUSGeoid2020 differs from AUSGeoid09 in two important ways.

(1) In 2017, the Geocentric Datum of Australia GDA2020 was made the new national standard for ellipsoidal heights. GDA2020 coordinates are aligned with the International Terrestrial Reference Frame 2014 (ITRF2014, Altamimi et al. 2016) extrapolated to the first of January 2020, and are approximately $1.8 \mathrm{~m}$ different to GDA94 coordinates in the horizontal North/North/East direction accounting for the $\sim 7 \mathrm{~cm} \mathrm{yr}^{-1}$ continental drift. Importantly, GDA2020 ellipsoidal heights also differ from GDA94 heights by up to $9 \mathrm{~cm}$ (ICSM 2020). The geometric layer (Fig. 2b) was determined by gridding the difference between GDA2020 ellipsoidal heights minus AHD heights and the gravimetric quasigeoid - for data points at 7624 locations - by least squares collocation (Brown et al. 2018).

(2) The AUSGeoid2020 model has an accompanying map of uncertainty estimates (Fig. 1b). The uncertainty estimates were calculated by propagating uncertainty estimates of the raw data through each stage of the processing. Gravity anomaly uncertainties were calculated from error estimates of the gravity data and positioning information, propagated through Stokes integral and combined with the published EGM2008 uncertainty grids in a remove-compute-restore scheme (Featherstone et al. 2018b). These were then augmented with the error propagation from the least squares collocation gridding of the geometric component. The uncertainty values provide a way for users of the model to calculate how precise their GPS/AUSGeoid2020 derived AHD heights may be.

\section{EXPERIMENTAL QUASIGEOID MODELS AND "PATCHING"}

\subsection{Patching an Error in Port Phillip Bay, Victoria, SE Australia}

Following the release of the AUSGeoid2020 model, a number of independent tests - using GDA2020 ellipsoidal heights and levelling data that were not included in AUSGeoid2020 - were conducted by State Government departments to ensure the model was precise and "fit for purpose". However, a test in Victoria identified a spike in the AUSGeoid2020 model in the vicinity of Melbourne and Geelong (Fig. 3).

Melbourne and Geelong are predominately built up around Port Phillip Bay - this is a Bay which covers an area of $\sim 2000 \mathrm{~km}^{2}$ with an average depth of only $8 \mathrm{~m}$ and opens into the Bass Strait through a very narrow channel. 
(a)

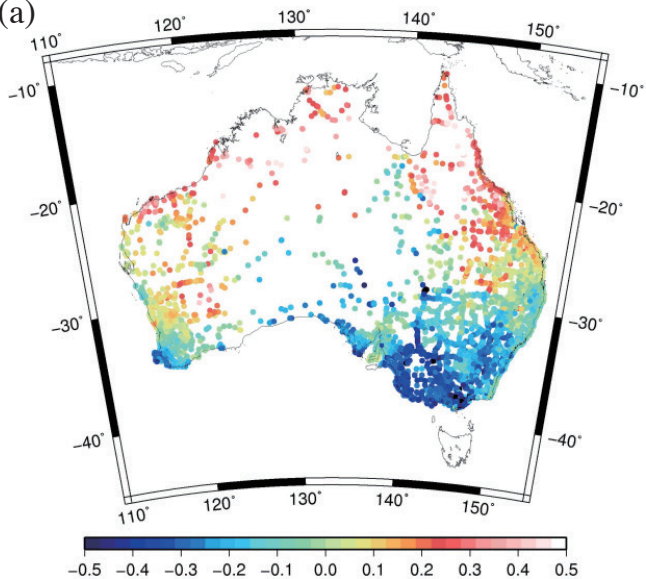

(b)

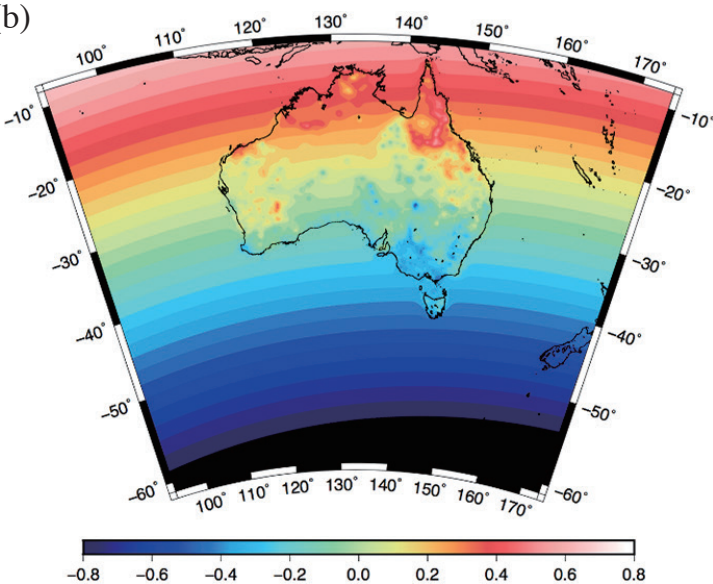

Fig. 2. (a) The difference between the gravity-only quasigeoid model and the 7624 GDA2020 ellipsoidal heights minus AHD heights, the scale bar is in metres. (b) The geometric layer of the AUSGeoid2020 model. The surface corresponds to the difference between the quasigeoid and where AHD heights are zero. The scale bar is in metres. In both cases, the north-south tilt in the AHD is evident, as well as some regional distortions. From Brown et al. (2018) and Featherstone et al. (2018b).
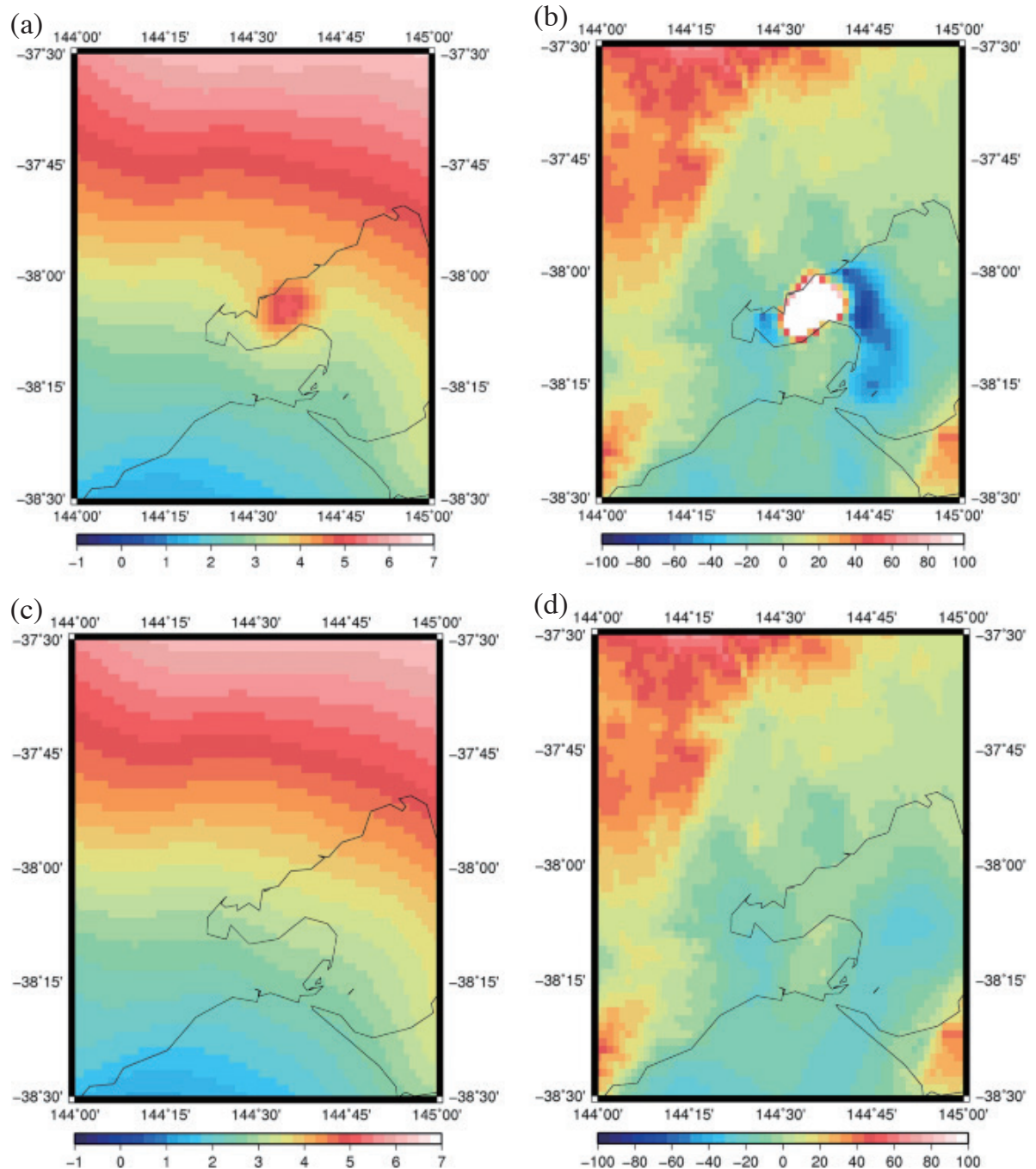

Fig. 3. (a) The AGQG2017 model (units in metres) before being corrected with the DTU15 altimetry gravity data over the Port Phillip Bay region. (b) The gravity anomaly (mGal) in the Sandwell et al. (2014) model, (c) the quasigeoid (units in metres) after the patch has been applied, (d) the gravity anomaly with DTU15 data offshore (units in mGal). From Brown et al. (2018). 
Offshore, gravity data in the underlying AGQG2017 gravimetric component of AUSGeoid2020 is determined entirely from satellite altimetry data - including within this bay. Altimetry data are notoriously unreliably over shallow water and in the near-shore zone (e.g., Deng et al. 2002).

The altimetry derived gravity anomaly used for AGQG2017 contained a $>50 \mathrm{mGal}$ spike, that carried onshore during the evaluation of Stokes's integral and resulted in a $>1 \mathrm{~m}$ error in AGQG2017 (Fig. 3). To remedy this error, we created a patch for the model by computing a new quasigeoid over a 5 by 5 degree area, centred over the bay, replacing the Sandwell et al. $(2013,2014)$ data with data from DTU15 (Andersen and Knudsen 2016) which did not contain a similar error. The patch was blended with the AGQG2017 model using a cosine taper (Appendix B, Brown et al. 2018).

\subsection{Fine-Scale Parameter Sweeps}

The computation of AGQG2017 evaluated Stokes's integral using the FEO Stokes kernel modification (Featherstone et al. 1998), with a range of modification degrees of $[0,40,60,80,100,120$, and 140$]$ and integration cap radii of 0 to 5 degrees in increments of 0.5 degrees. In total, we computed 77 individual quasigeoid solutions. The choice of parameters (identified to be a modification degree of $\mathrm{M}=$ 40 and integration cap radius of 0.5 degrees on comparison to GPS ellipsoidal minus AHD heights) was somewhat towards the edges of the explored parameter ranges.

To investigate whether any improvements could be made to these parameter choices, we conducted a fine-scale parameter sweep, exploring modification degrees range from 0 to 360 in increments of 10 degrees and integration cap radii between 0 and 5 degrees in increments of 0.1 degrees. We further explored the use of additional deterministic kernel modification schemes, namely the unmodified spherical Stokes kernel, Wong and Gore (1969), Meissl (1971), Heck and Gruninger (1987), and Vaníček and Kleusberg (1987) [also see Vaníček and Sjöberg (1991)] modification schemes. In total, this produced more than 10000 separate quasigeoid solutions.

Each quasigeoid model was then compared to (1) GDA2020 ellipsoidal heights minus AHD heights, and also (2) GDA2020 ellipsoidal heights minus a readjustment of the AHD levelling height data which were minimally constrained to just a single point and had normal corrections applied (as described in Featherstone et al. 2018a). The intention of using the second ground truth dataset was to further mitigate any issues associated with using "official" AHD heights that are contaminated by a slope originating from the ocean's mean dynamic topography (Featherstone and Filmer 2012).

The results (Figs. 4 to 9) indicate that (1) the parameter choices made for AGQG2017 was near optimal in terms of the agreement of the model to GDA2020 ellipsoidal minus AHD levelling heights (approx. $\pm 185 \mathrm{~mm}$ ). (2) The Vaníček and Kleusberg (1987) and Featherstone et al. (1998) kernels become unstable for high modification degrees $(>150)$ and larger integration cap radii ( $>2$ degrees). It is not entirely clear where the instability arises from. Both these kernel modification schemes require that a system of linear equations are solved (Featherstone et al. 1998). One candidate for the instability is the matrix inversion required to solve these equations (which increases in size with the modification degree), but this needs further investigation. Future computations should exercise care to ensure the instability does not influence results. The minimum value here for these two kernel modifications actually lies within this area of instability and so it should be interpreted with caution.

\subsection{Planar Terrain Corrections Versus the Molodensky G Series}

The height anomaly/quasigeoid is the solution to the Molodensky boundary value problem and the solution can be obtained by using Stokes's integral with the Molodensky gravity anomaly on the Earth's surface (Molodensky et al. 1960, 1962; Heiskanen and Moritz 1967). The gravitational effect of topography is expressed as an infinite power series of convolution integrals of the Molodensky free air anomalies and normal heights (McCubbine et al. 2019). For regional quasigeoid computations only the first term, $G_{1}$ [Eq. (3)], is generally considered (Burša 1965; Rapp 1975; Amod and Merry 2002; Merry 2003).

The classical planar terrain correction, $\Delta g_{T C}$ [Eq. (4)] was used in place of the $G_{1}$ term for the computation of AGQG2017 as an approximation. To investigate the effect of this approximation on the accuracy of the quasigeoid model, we computed $G_{1}$ terms and recomputed the series of quasigeoid models, exploring the same ranges of Stokes modification parameters and integration cap radii as used for AGQG2017 (Featherstone et al. 2018a). However, using $G_{1}$ value rather than $\Delta g_{T C}$ resulted in a worse fit of the quasigeoid to GDA2020 ellipsoidal heights minus AHD heights.

$$
\begin{aligned}
\Delta g_{T C}(x, y)= & \frac{\Delta x \Delta y G \rho}{2}\left\{H(x, y)^{2}\left[1 \circledast \frac{1}{l\left(x, y, x^{\prime}, y^{\prime}\right)^{3}}\right]-\right. \\
& 2 H(x, y)\left[H\left(x^{\prime}, y^{\prime}\right) \circledast \frac{1}{l\left(x, y, x^{\prime}, y^{\prime}\right)^{3}}\right]+ \\
& {\left.\left[\frac{1}{l\left(x, y, x^{\prime}, y^{\prime}\right)^{3}} \circledast H\left(x^{\prime}, y^{\prime}\right)^{2}\right]\right\} }
\end{aligned}
$$

$G_{1}(\phi, \lambda)=$

$\frac{\Delta \phi \Delta \lambda}{2 \pi}\left[H(\phi, \lambda) \Delta g_{F A}(\phi, \lambda) \circledast \frac{1}{l\left(\phi, \lambda, \phi^{\prime}, \lambda^{\prime}\right)^{3}}-\right.$ 

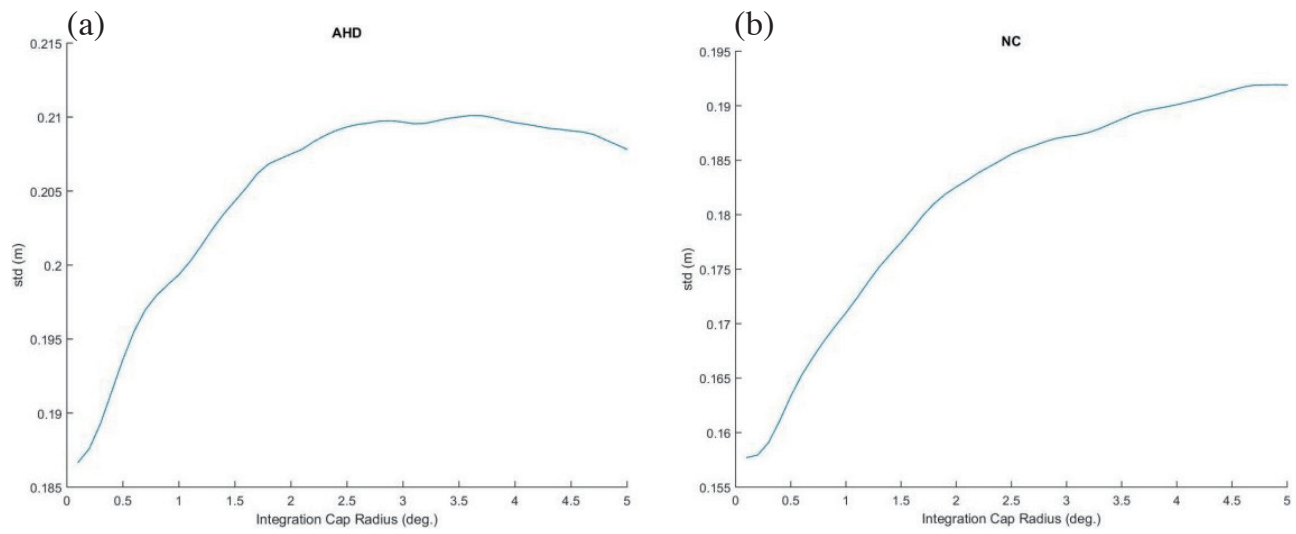

Fig. 4. (a) Standard deviation of quasigeoids determined with the unmodified Stokes kernel for integration cap radii 0 - 5 degrees compared to GDA2020 ellipsoidal minus AHD levelling heights. (b) Standard deviation of quasigeoids determined with unmodified Stokes kernel for integration cap radii 0 - 5 degrees compared to GDA2020 ellipsoidal minus minimally constrained levelling heights with normal corrections applied. Minima are found with integration cap radius at 0.1 degrees. The worsening results with increased integration radii is because the unmodified kernel is allowing long wavelength terrestrial gravity data errors to contaminate the solution because it does not possess any additional partial high-pass filtering properties.

(a)

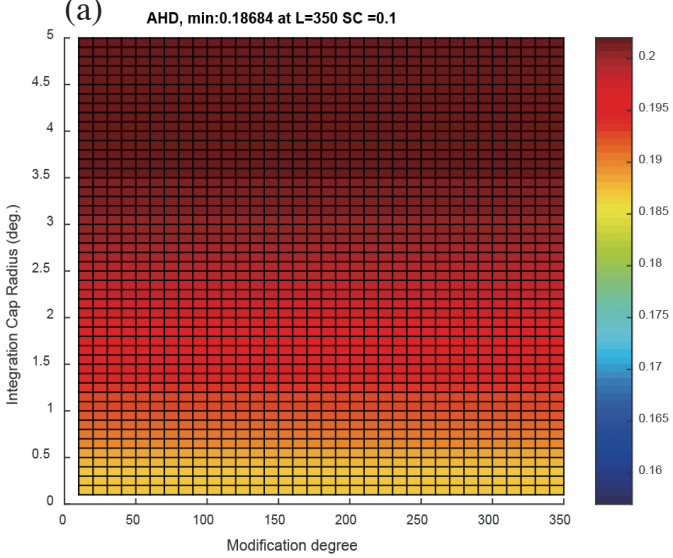

(b)

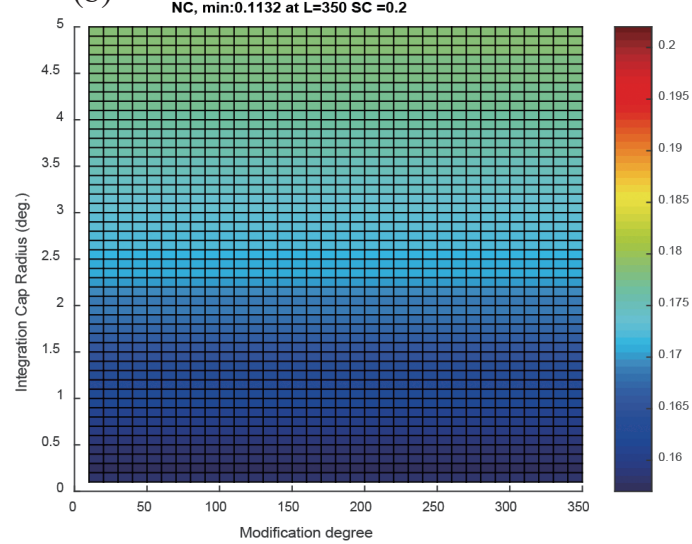

Fig. 5. (a) Standard deviation of quasigeoids determined with Meissl modified Stokes kernel for integration cap radii 0 - 5 degrees compared to GDA2020 ellipsoidal minus AHD levelling heights. Minimum is found with integration cap radius at 0.1 degrees and with modification degree of 350. (b) Standard deviation of quasigeoids determined with Meissl modified Stokes kernel for integration cap radii $0-5$ degrees compared to GDA2020 ellipsoidal minus minimally constrained levelling heights with normal corrections applied. Minimum is found with integration cap radius at 0.2 degrees and with modification degree of 350 .

(a)

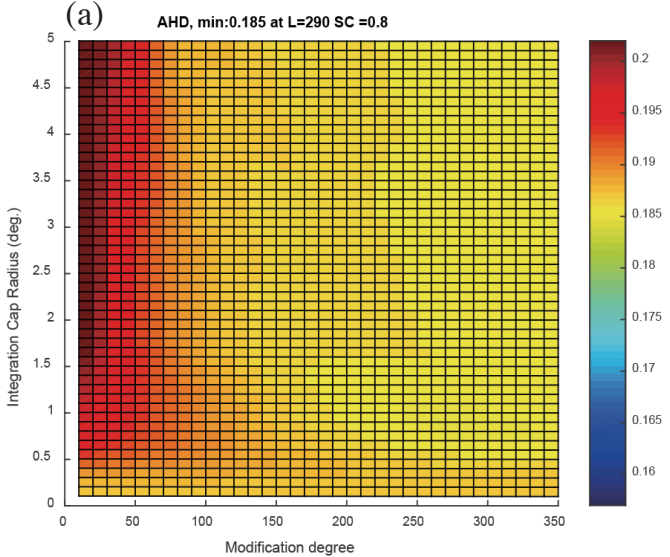

(b)

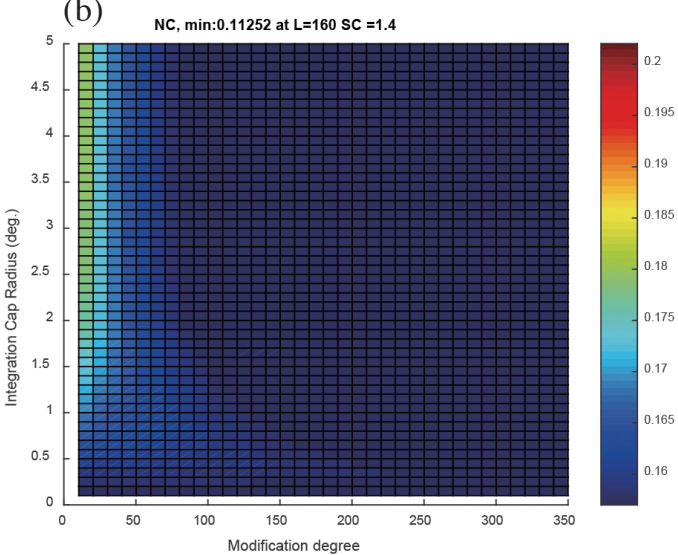

Fig. 6. Same as Fig. 5 but for the Heck and Gruninger (1987) kernel. Minimum is found with integration cap radius at 1.4 degrees and with modification degree of 160 . 
(a) AHD, $\min : 0.18425$ at $L=280 \mathrm{SC}=1.1$

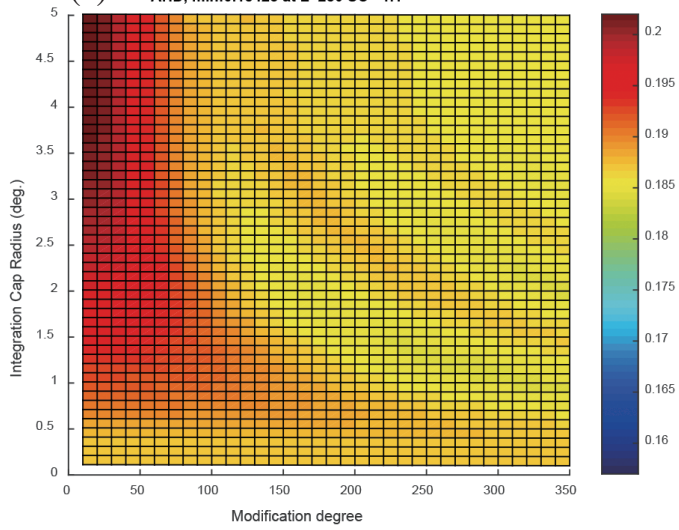

(b)

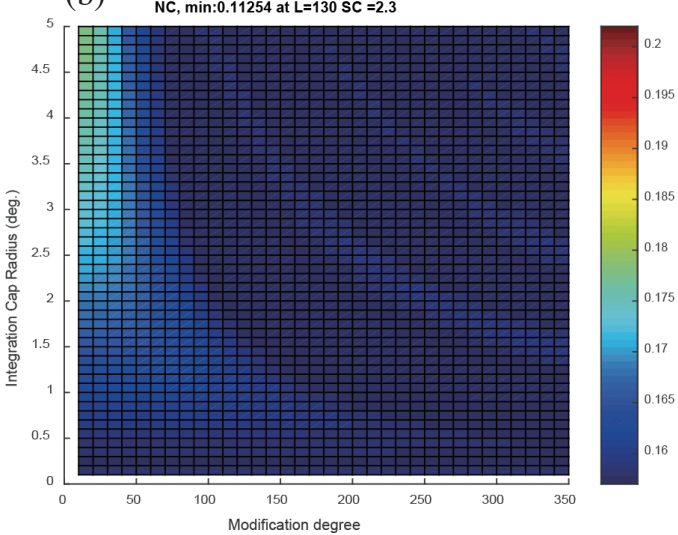

Fig. 7. Same as Fig. 5 but for the Wong and Gore (1969) kernel. Minimum is found with integration cap radius at 2.3 degrees and with modification degree of 130 .

(a)

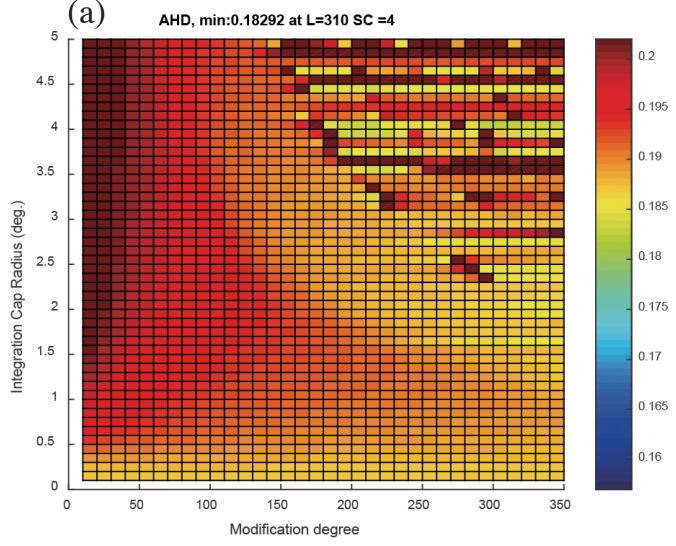

(b)

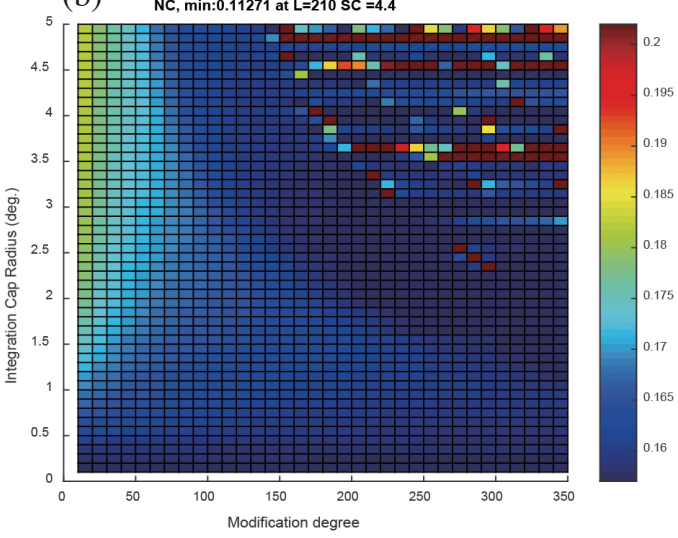

Fig. 8. Same as Fig. 5 but for the Vaníček and Kleusberg (1987) kernel. Minimum is found with integration cap radius at 4.4 degrees and with modification degree of 210 . The kernel instability can be seen in the top right of the parameter sweep ranges. Note that the minima are within this area and potentially unreliable.

(a)

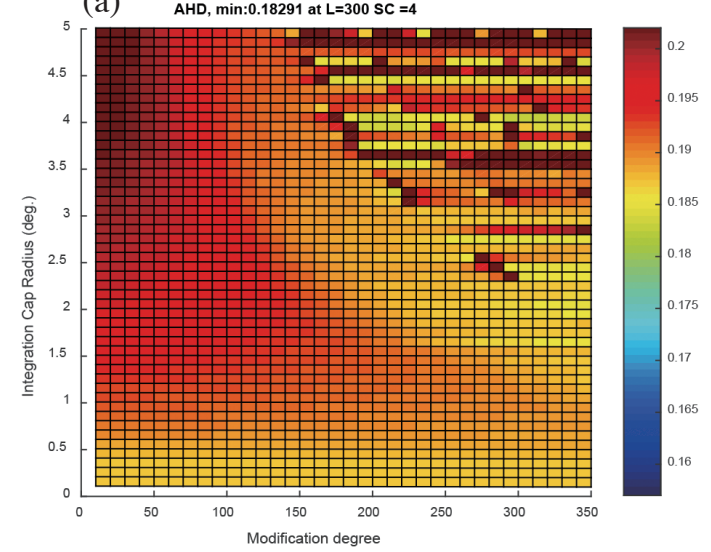

(b)

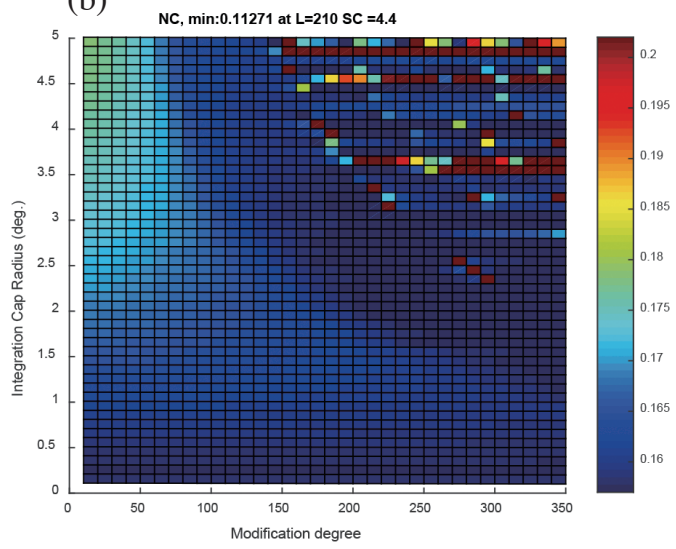

Fig. 9. Same as Fig. 5 but for the Featherstone et al. (1998) kernel. Minimum is found with integration cap radius at 4.4 degrees and with modification degree of 210 . The kernel instability can be seen in the top right of the parameter sweep ranges. Note that the minimums are within this area and potentially unreliable. 
The $G_{1}$ value and gravimetric terrain corrections used in the computation of AGQG2017, were calculated at the same resolution as the digital elevation model (DEM), a high resolution 1 arc second grid $(\sim 30 \mathrm{~m})$. For the $G_{1}$ terms, this required a grid of free-air gravity anomalies to also be available at the same resolution as the DEM. This made it necessary to grid the gravity data at an unrealistically high resolution given the $\sim 4 \mathrm{~km}^{2}$ on-average gravity observation spacing. We suspect this to be the cause of the unexpected worsening of the fit of the quasigeoid model to the GDA2020 ellipsoidal heights minus AHD heights.

To investigate this issue, we further recomputed both the terrain corrections and $G_{1}$ terms using a block-averaged DEM and 1 arc minute grid (equivalent to the resolution of the AGQG2017 model) and produced another suite of quasigeoid models. While in this instance the Molodensky gravity anomaly with the $G_{1}$ terms gave the superior fit to the GDA2020 ellipsoidal heights minus AHD heights, using the 1 arc second planar terrain correction still gave the best result (Fig. 10). Note that this conclusion is not definitive because of errors in all the data used. For instance, the formal error budget for the GPS-levelling data is $\sim 40 \mathrm{~mm}$ on average (Featherstone et al. 2019), which is larger than the change in standard deviations in Fig. 10.

\subsection{Potential Improvements to Be Offered by Airborne Gravimetry Data}

In 2011, an airborne gravity survey was conducted over the Gippsland Basin in southern Victoria, SE Australia. The survey covered the littoral zone up to $40 \mathrm{~km}$ offshore and $10-20 \mathrm{~km}$ onshore and was conducted as a part of the Victorian Government's CarbonNet Project for geological modelling of subsurface structure for potential carbon dioxide sequestration. Over this offshore area, the gravity data used for AGQG2017 is derived from satellite altimetry - and are generally unreliable close to the coast (e.g., Deng et al. 2002).

We have compared these airborne gravity data (Fig. 11a) to the gravity anomalies used to compute the AGQG2017 model and see differences with a range of around $9 \mathrm{mGal}$ and a near-zero mean. The comparison was made by interpolating the 1 arc minute gridded AGQG2017 gravity anomaly to the location of the airborne data and calculating the difference. The interpolation was carried out using least squares collocation, with a 3D logarithmic covariance function (Forsberg 1987), in a remove-computerestore procedure with EGM2008 to degree 2170 acting as the reference field. The differences (Fig. 11b) are typically largest onshore in areas where the terrestrial gravity data thin out, and offshore where the altimetry derived gravity anomalies are unreliable.

Wu et al. (2019) explored the benefit that these data offer to the quasigeoid modelling in this coastal region. How- ever, there is only a limited number $(<30)$ of GDA2020 ellipsoidal and levelled heights onshore in this region - so these data offer very little statistical power for assessing the precision of any local quasigeoid model. Instead, Wu et al. (2019) compared quasigeoid models computed with and without the airborne gravity data to independent altimetry derived geoid heights. The comparison to the quasigeoid determined without the airborne data was $\pm 28 \mathrm{~mm}$, including the airborne gravity data improved the agreement by $5 \mathrm{~mm}-$ down to $\pm 23 \mathrm{~mm}$. This constituted a potential $20 \%$ improvement, however, these data have not yet been assimilated into the Australian quasigeoid model.

\section{FUTURE PLANS AND THE AUSTRALIAN VERTICAL WORKING SURFACE (AVWS)}

The AHD is a normal-orthometric height system and was realised at a series of differential levelling benchmarks from a constrained and staged least squares adjustment (Roelse et al. 1971). In principle, it is a levelling-only datum (Filmer and Featherstone 2012b). The last 20 years of geoid modelling in Australia has revealed the 1971 realisation of the AHD introduced features that are not related to the Earth's gravity field (e.g., Featherstone and Filmer 2012) and alternatives to AHD have been discussed (e.g., Featherstone et al. 2012). The geometric layer in AUSGeoid09/2020 attempts to ameliorate these features, but this datum deficiency remains problematic. Firstly, the geometric component has no physical interpretation offshore and so the model must be clipped at the coastline (Fig. 1). This causes difficulties in instances where a seamless onshore/offshore datum is needed, e.g., to align bathymetric and topographic elevation models. Secondly, they are difficult to estimate where no AHD levelling data are available and must be interpolated from nearby values (sometimes $>100 \mathrm{~km}$ away).

The inclusion of the geometric layer in AUSGeoid2020 distorts the quasigeoid to fit these features of the AHD and, in doing so, degrades the quality of the model to act as a reference surface for truly physically meaningful heights. For this reason, AUSGeoid2020 will most likely be the last national model of the AHD reference surface. The AVWS (Australian vertical working surface) is an alternative vertical reference frame comprising a normal height system with a quasigeoid model (ICSM 2021). The model currently underpinning the AVWS is AGQG2017, the gravimetric component of the AUSGeoid2020 model - aligned with GRS80 by the application of a zero degree term (ICSM 2021). Much like AUSGeoid2020, the AGQG2017 has a companion grid of uncertainty estimates - and these are generally half the size of their AUSGeoid2020 counterparts (cf. Figs. $1 \mathrm{~b}$ and $12 \mathrm{~b}$ ). The AVWS is directly compatible with GDA2020 ellipsoidal heights, since both reference GRS80, however it is also still compatible with heights established via differential levelling when connected to a location with 

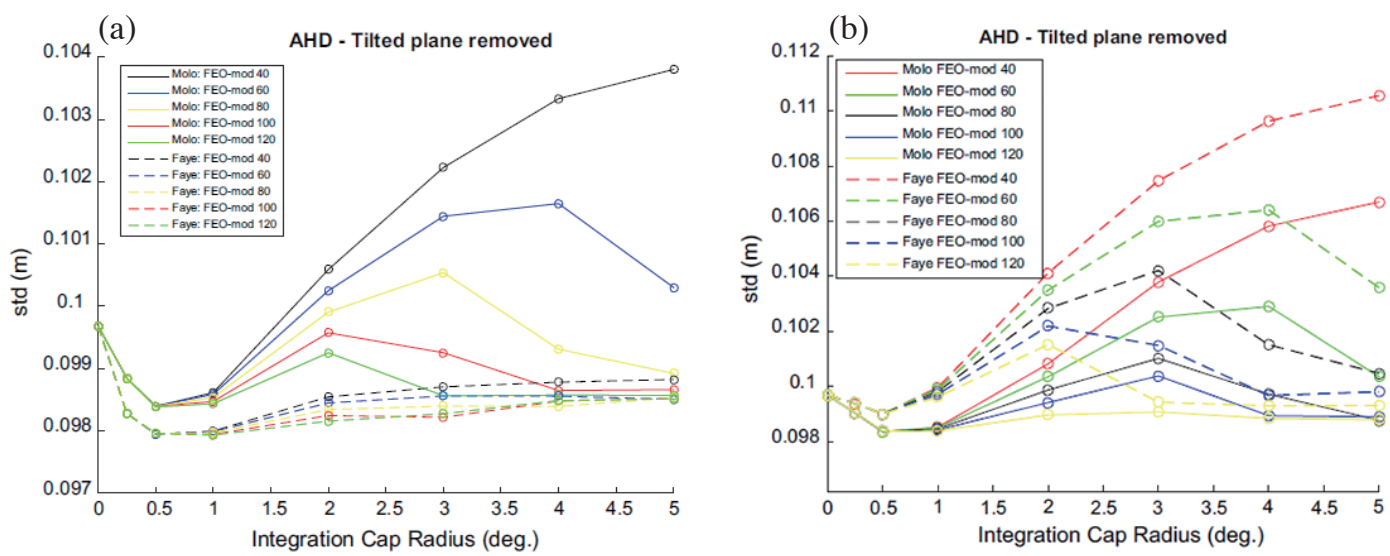

Fig. 10. (a) Standard deviations (m) of gravimetric quasigeoid models for parameter sweeps of the FEO kernel modification degree and spherical integration cap radius versus GNSS-levelling data after removal of a tilted plane using the G1 term (solid lines) and the planar terrain correction (dashed lines - from Featherstone et al. 2018a), both determined from 1" $\times 1$ " grids. (b) Standard deviations (m) of gravimetric quasigeoid models for parameter sweeps of FEO kernel modification degree and spherical integration cap radius versus GNSS-levelling data after removal of a tilted plane using the G1 term (solid lines) and the planar terrain corrections, both determined from 1' $\times 1$ ' grids. From McCubbine et al. (2019).
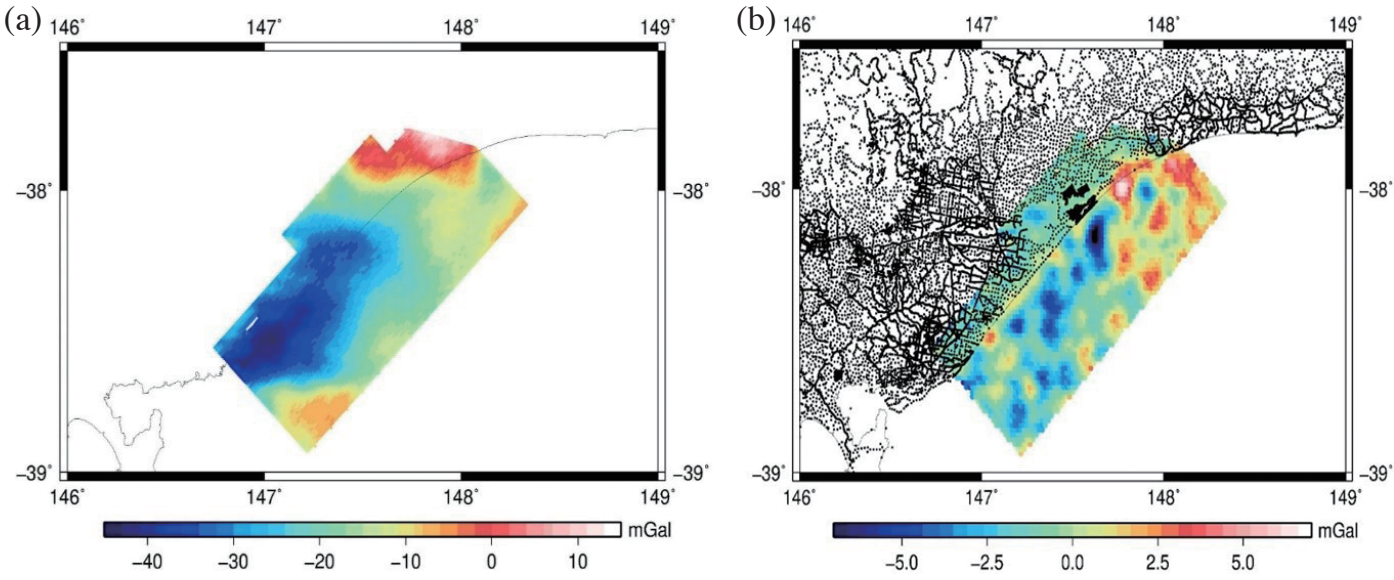

Fig. 11. (a) Free air gravity anomalies over the Gippsland region determined from airborne gravimetry data. (b) Difference between gravity anomalies used to compute AGQG2017 and the airborne gravimetry derived gravity anomalies - black marks correspond to the locations of the terrestrial gravity data (min: -9.2 , max: 8.2 , mean: -0.02, STD: \pm 2.1 ) mGal.
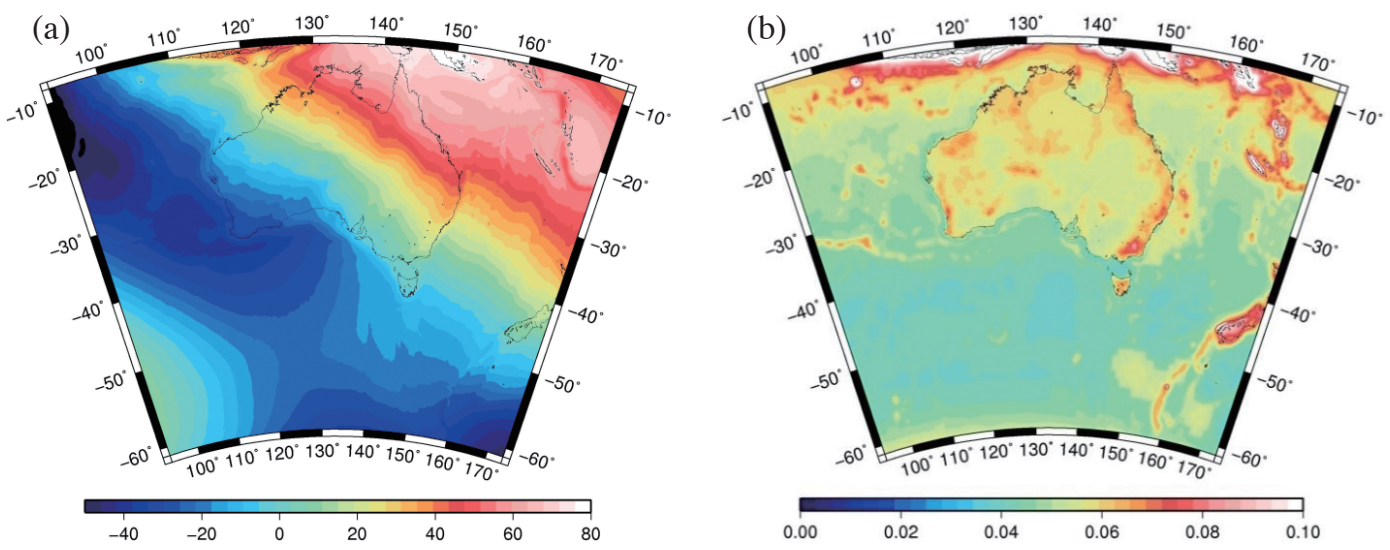

Fig. 12. (a) The AGQG2017 model separation from the GRS80 reference ellipsoid, the scale bar is in metres. (b) The propagated uncertainty in the AGQG2017 model, the scale bar is in metres. From Featherstone et al. (2018b). 
a known GDA2020 ellipsoidal height.

The focus for quasigeoid modelling in Australia is now to refine the AGQGyyyy model by improving the underlying data used to compute it, as well as investigating improved processing routines. This will be achieved by collecting airborne gravimetry observations that densify the existing terrestrial gravity data coverage onshore and improve the quality of the gravity data across the littoral zone. Data collection is currently planned over Greater Adelaide (GA, Fig. 13a) and Greater Melbourne (GM) and the Eastern Victoria Highlands (EVH, Fig. 13b). GA and GM are two major urban areas in Australia that are located within $50 \mathrm{~km}$ of the coast where the quasigeoid model is likely to be impacted by erroneous altimetry-derived gravity anomalies. The EVH has been prioritised because the terrestrial gravity data coverage is particularly sparse (mainly due to inaccessibility) and corresponds to an area of large formal uncertainty in the AGQG2017 model. The planned flight lines are spaced $5 \mathrm{~km}$ apart over GA, $2 \mathrm{~km}$ over GM, and $500 \mathrm{~m}$ over the EVH and data will be collected at a maximum height of around $160 \mathrm{~m}$ above the terrain, where it is safe to do so. The intention is to ultimately drive the uncertainty in the model down to $2-3 \mathrm{~cm}-$ starting with high impact, urban, areas where the model is of utility to most users.

\section{CONCLUDING REMARKS}

We have provided a historical review of regional geoid and quasigeoid modelling over the Australian continent. The earliest models were produced in the late 1960s and were used to reduce geodetic surveying measurements to the Australian National Spheroid associated with the nongeocentric Australian Geodetic Datum. Following the intro- duction of the AHD in 1971, and the introduction of GPS in the mid-1980s, the main reason for modelling the geoid was altered so as to allow for ellipsoidal heights (determined from GPS) to be transformed into AHD heights.

With the computation of AUSGeoid98, a number of flaws in the 1971 realisation of AHD heights became evident. To enable users to determine AHD heights more precisely, these flaws were assimilated into two subsequent geoid model computations, AUSGeoid09 and AUSGeoid2020. However, it is now recognised that distorting the models into better agreement with the AHD significantly degrades their accuracy and their ability act as a reference surface for meaningful physical heights. The underlying "gravimetric-only" layer of the AUSGeoid2020 has been released officially to support users who want to determine physical heights more preciseely and reliably. This new model underpins an alternative vertical height system called AVWS (Australian vertical working surface).

Experiments have been conducted to investigate whether there is scope to improve the computational process used to produce the AGQG model. In particular, (1) a fine-scale parameter sweep of Stokes kernel modification types, modification degrees and integration cap radii has been used to produce more than 10000 quasigeoid models, and (2) the effect of approximating the Molodensky series using planar terrain corrections has been scrutinised. The results indicate that the process used to produce AGQG2017 is adequate, given the availability of current gravity data and the limitations of the GPS-AHD heights used to assess the experimental quasigeoid models. The future direction of Australian quasigeoid modelling is to improve the underlying gravity data used to produce it. This will be accomplished by collecting airborne gravimetry data to regularise (a)
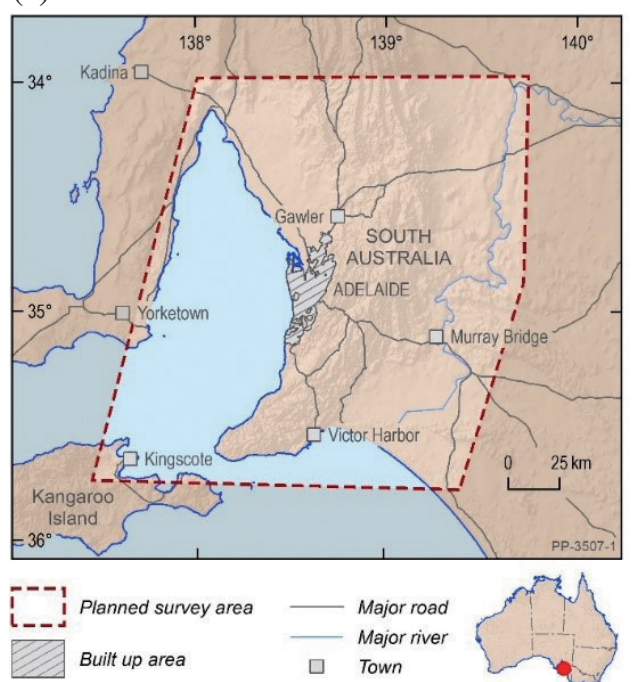

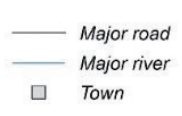

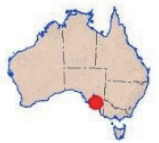

(b)

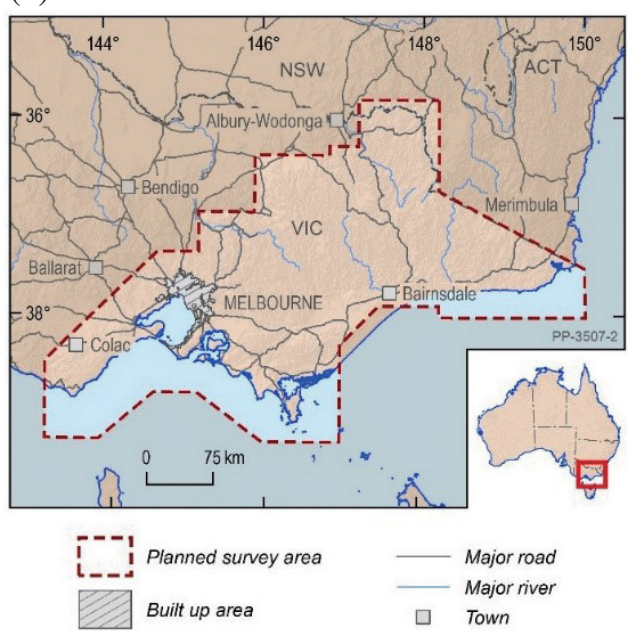

Fig. 13. (a) The extent of the planned (2021/22) South Australia airborne gravity survey centred over Greater Adelaide. (b) The extent of the planned (2021/22) Victoria airborne gravity survey over Greater Melbourne and Eastern Victoria Highlands. 
the existing data coverage onshore and improve the quality of the existing gravity data over the littoral zone.

Acknowledgements Maps and charts in this paper were produced using GMT, the Generic Mapping Tools (Wessel et al. 2013). Jack McCubbine and Nicholas Brown publish this paper with the permission of the Chief Executive Officer of Geoscience Australia. Will Featherstone thanks and acknowledges many years of research funding from the Australian Research Council, Western Australian State Government, Curtin University and the Cooperative Research Centre for Spatial Information for quasi/geoid research and computation. We also thank the editor and two anonymous reviewers for their very prompt reviews of this manuscript.

\section{REFERENCES}

Altamimi, Z., P. Rebischung, L. Métivier, and X. Collilieux, 2016: ITRF2014: A new release of the International Terrestrial Reference Frame modeling nonlinear station motions. J. Geophys. Res., 121, 6109-6131, doi: 10.1002/2016JB013098. [Link]

Amod, A. and C. L. Merry, 2002: A note on the Molodensky G1 term. International Geoid Service Bulletin, 12, 62-80.

Andersen, O. B. and P. Knudsen, 2016: Deriving the DTU15 Global high resolution marine gravity field from satellite altimetry. ESA Living Planet Symposium, Prague, Czech Republic.

Brown, N. J., W. E. Featherstone, G. Hu, and G. M. Johnston, 2011: AUSGeoid09: A more direct and more accurate model for converting ellipsoidal heights to AHD heights. J. Spat. Sci., 56, 27-37, doi: 10.1080/14498596.2011.580498. [Link]

Brown, N. J., J. C. McCubbine, W. E. Featherstone, N. Gowans, A. Woods, and I. Baran, 2018: AUSGeoid2020 combined gravimetric-geometric model: Location-specific uncertainties and baseline-length-dependent error decorrelation. J. Geod., 92, 1457-1465, doi: 10.1007/s00190-018-1202-7. [Link]

Burša, M., 1965: On practical application of the solution of Molodensky's integral equation in the first approximation. Stud. Geophys. Geod., 9, 144-150, doi: 10.1007/ BF02607323. [Link]

Claessens, S. J., W. E. Featherstone, and F. Barthelmes, 2001: Experiences with point-mass gravity field modelling in the Perth region, Western Australia. Geomatics Research Australasia, 75, 53-86.

Darbeheshti, N. and W. E. Featherstone, 2009: Non-stationary covariance function modelling in 2D least-squares collocation. J. Geod., 83, 495-508, doi: 10.1007/ s00190-008-0267-0. [Link]

Darbeheshti, N. and W. E. Featherstone, 2010: Tuning a gravimetric quasigeoid to GPS-levelling by non-sta- tionary least-squares collocation. J. Geod., 84, 419431, doi: 10.1007/s00190-010-0377-3. [Link]

Deng, X., W. E. Featherstone, C. Hwang, and P. A. M. Berry, 2002: Estimation of contamination of ERS-2 and POSEIDON satellite radar altimetry close to the coasts of Australia. Mar. Geod., 25, 249-271, doi: 10.1080/01490410214990. [Link]

Featherstone, W. E., 1994: An explanation of the Geocentric Datum of Australia and its effects upon future mapping. Cartography, 23, 1-12, doi: 10.1080/00690805.1994.9713978. [Link]

Featherstone, W. E., 1998: Do we need a gravimetric geoid or a model of the Australian Height Datum to transform GPS heights in Australia? Australian Surveyor, 43, 273-280, doi: 10.1080/00050350.1998.10558758. [Link]

Featherstone, W. E., 1999: A comparison of gravimetric geoid models over Western Australia, computed using modified forms of Stokes's integral. Journal of the Royal Society of Western Australia, 82, 137-145.

Featherstone, W. E., 2000a: Refinement of gravimetric geoid using GPS and leveling data. J. Surv. Eng., 126, 2756, doi: 10.1061/(ASCE)0733-9453(2000)126:2(27). [Link]

Featherstone, W. E., 2000b: Towards the unification of the Australian Height Datum between mainland and Tasmania using GPS and AUSGeoid98. Geomatics Research Australasia, 73, 33-54.

Featherstone, W. E., 2004: Evidence of a north-south trend between AUSGeoid98 and the Australian Height Datum in southwest Australia. Surv. Rev., 37, 334-343, doi: 10.1179/sre.2004.37.291.334. [Link]

Featherstone, W. E., 2006: Yet more evidence for a northsouth slope in the Australian Height Datum. J. Spat. Sci., 51, 1-6, doi: 10.1080/14498596.2006.9635076. [Link]

Featherstone, W. E., 2008: GNSS-based heighting in Australia: Current, emerging and future issues. J. Spat.Sci., 53, 115-133, doi: 10.1080/14498596.2008.9635153. [Link]

Featherstone, W. E., 2009: Only use ship-track gravity data with caution: A case-study around Australia. Aust. J. Earth Sci., 56, 195-199, doi: 10.1080/08120090802547025. [Link]

Featherstone, W. E. and M. S. Filmer, 2008: A new GPSbased evaluation of distortions in the Australian Height Datum in Western Australia. Journal of the Royal Society of Western Australia, 91, 199-206.

Featherstone, W.E. and M. S. Filmer, 2012: The north-south tilt in the Australian Height Datum is explained by the ocean's mean dynamic topography. J. Geophys. Res., 117, C08035, doi: 10.1029/2012JC007974. [Link]

Featherstone, W. E. and J. F. Kirby, 1998: Estimates of the separation between the geoid and the quasigeoid over 
Australia. Geomatics Research Australasia, 68, 79-90.

Featherstone, W. E. and J. F. Kirby, 2000: The reduction of aliasing in gravity anomalies and geoid heights using digital terrain data. Geophys. J. Int., 141, 204-212, doi: 10.1046/j.1365-246X.2000.00082.x. [Link]

Featherstone, W. E. and M. Kuhn, 2006: Height systems and vertical datums: A review in the Australian context. J. Spat. Sci., 51, 21-41, doi: 10.1080/14498596.2006.9635062. [Link]

Featherstone, W. E. and D. D. Lichti, 2009: Fitting gravimetric geoid models to vertical deflections. J. Geod., 83, 583-589, doi: 10.1007/s00190-008-0263-4. [Link]

Featherstone, W. E. and L. Morgan, 2007: Validation of the AUSGeoid98 model in Western Australia using historic astrogeodetically observed deviations of the vertical. Journal of the Royal Society of Western Australia, 90, 143-149.

Featherstone, W. E. and D. M. Sproule, 2006: Fitting AUSGeoid98 to the Australian Height Datum using GPSlevelling and least squares collocation: Application of a cross-validation technique. Surv. Rev., 38, 573-582, doi: 10.1179/sre.2006.38.301.573. [Link]

Featherstone, W. E. and M. P. Stewart, 1998: Possible evidence for distortions in the Australian Height Datum in Western Australia. Geomatics Research Australasia, 68, 1-12.

Featherstone, W. E., J. D. Evans, and J. G. Olliver, 1998: A Meissl-modified Vaníček and Kleusberg kernel to reduce the truncation error in gravimetric geoid computations. J. Geod., 72, 154-160, doi: 10.1007/ s001900050157. [Link]

Featherstone, W. E., J. F. Kirby, A. H. W. Kearsley, J. R. Gilliland, G. M. Johnston, J. Steed, R. Forsberg, and M. G. Sideris, 2001: The AUSGeoid98 geoid model of Australia: Data treatment, computations and comparisons with GPS-levelling data. J. Geod., 75, 313-330, doi: 10.1007/s001900100177. [Link]

Featherstone, W. E., J. F. Kirby, C. Hirt, M. S. Filmer, S. J. Claessens, N. J. Brown, G. Hu, and G. M. Johnston, 2011: The AUSGeoid09 model of the Australian height datum. J. Geod., 85, 133-150, doi: 10.1007/ s00190-010-0422-2. [Link]

Featherstone, W. E., M. S. Filmer, S. J. Claessens, M. Kuhn, C. Hirt, and J. F. Kirby, 2012: Regional geoid-modelbased vertical datums - some Australian perspectives. J. Geod. Sci., 2, 370-376, doi: 10.2478/v10156-0120006-6. [Link]

Featherstone, W. E., N. J. Brown, J. C. McCubbine, and M. S. Filmer, 2018a: Description and release of Australian gravity field model testing data. Aust. J. Earth Sci., 65, 1-7, doi: 10.1080/08120099.2018.1412353. [Link]

Featherstone, W. E., J. C. McCubbine, N. J. Brown, S. J. Claessens, M. S. Filmer, and J. F. Kirby, 2018b: The first Australian gravimetric quasigeoid model with location-specific uncertainty estimates. J. Geod., 92, 149-168, doi: 10.1007/s00190-017-1053-7. [Link]

Featherstone, W.E.,J.C.McCubbine, S.J.Claessens, D. Belton, and N. J. Brown, 2019: Using AUSGeoid2020 and its error grids in surveying computations. J. Spat. Sci., 64, 363-380, doi: 10.1080/14498596.2018.1559774. [Link]

Filmer, M. S. and W.E. Featherstone, 2009: Detecting spiritlevelling errors in the AHD: Recent findings and issues for any new Australian height datum. Aust. J. Earth Sci., 56, 559-569, doi: 10.1080/08120090902806305. [Link]

Filmer, M. S. and W. E. Featherstone, 2012a: A re-evaluation of the offset in the Australian Height Datum between mainland Australia and Tasmania. Mar. Geod., 35, 107-119, doi: 10.1080/01490419.2011.634961. [Link]

Filmer, M. S. and W. E. Featherstone, 2012b: Three viable options for a new Australian vertical datum. J. Spat. Sci., 57, 19-36, doi: 10.1080/14498596.2012.679248. [Link]

Filmer, M. S., W. E. Featherstone, and M. Kuhn, 2010: The effect of EGM2008-based normal, normal-orthometric and Helmert orthometric height systems on the Australian levelling network. J. Geod., 84, 501-513, doi: 10.1007/s00190-010-0388-0. [Link]

Fischer, I. and M. Slutsky, 1967: A preliminary geoid chart of Australia. Australian Surveyor, 21, 327-332, doi: 10.1080/00050326.1967.10440069. [Link]

Forsberg, R., 1987: A new covariance model for inertial gravimetry and gradiometry. J. Geophys. Res., 92, 1305-1310, doi: 10.1029/JB092iB02p01305. [Link]

Fraser, A. R., F. J. Moss, and A. Turpie, 1976: Reconnaissance gravity survey of Australia. Geophysics, 41, 1337-1345, doi: 10.1190/1.1440683. [Link]

Freund, K. A., J. Steed, and A.H.W. Kearsley, 1997: A geoid for the Australian Capital Territory. Australian Surveyor, 42, 25-32, doi: 10.1080/00050342.1997.10558663. [Link]

Fryer, J. G., 1971: The geoid in Australia - 1971. Technical Report 13, Department of Minerals and Energy, Division of National Mapping, Canberra, Australia, 16 pp.

Fryer,J.G., 1972: The Australian geoid.Australian Surveyor, 24, 203-214, doi: 10.1080/00050326.1972.10440630. [Link]

Gilliland, J. R., 1987: An Australian gravity anomaly data bank for geoid determinations. Australian Surveyor, 33, 578-581, doi: 10.1080/00050326.1987.10438959. [Link]

Gilliland, J. R., 1989: A gravimetric geoid of Australia. Australian Surveyor, 34, 699-706, doi: 10.1080/00050326.1989.10438602. [Link]

Goos, J. M., W. E. Featherstone, J. F. Kirby, and S. A. Holmes, 2003: Experiments with two different 
approaches to gridding terrestrial gravity anomalies and their effect on regional geoid computation. Surv. Rev., 37, 92-112, doi: 10.1179/sre.2003.37.288.92. [Link]

Grushinsky, N. P., N. B. Sazhina, and D. A. Brown, 1971: The gravitational field and the Geoid of Australia. Journal of the Geological Society of Australia, 18, 183-199, doi: 10.1080/00167617108728758. [Link]

Haagmans, R., E. de Min, and M. van Gelderen, 1993: Fast evaluation of convolution integrals on the sphere using 1D FFT, and a comparison with existing methods for Stokes' integral. Manuscr. Geod., 18, 227-241.

Heck, B. and W. Gruninger, 1987: Modification of Stokes' integral formula by combining two classical approaches. IUGG General Assembly, Vancouver, 319-337.

Heiskanen, W. A. and H. Moritz, 1967: Physical Geodesy, W. H. Freeman and Company, San Francisco, USA, $364 \mathrm{pp}$.

ICSM, 1996: Standards and specifications for control surveys. Special Publication No. 1, Inter-Governmental Committee on Surveying and Mapping, Canberra, Australia.

ICSM, 2020: Geocentric Datum of Australia 2020 Technical Manual, Version 1.5, Intergovernmental Committee on Surveying and Mapping, 78 pp (Last viewed 18/05/2021). Available at https://www.icsm.gov.au/ sites/default/files/2020-12/GDA2020\%20Technical\%20Manual\%20V1.5 4.pdf.

ICSM, 2021: Australian Vertical Working Surface Technical Implementation Plan, Version 1.5, 25 pp (Last viewed 18/05/2021). Available at https://www.icsm. gov.au/publications/australian-vertical-working-surface-technical-implementation-plan-v15.

Kearsley, A. H. W., 1985: Towards the optimum evaluation of the inner zone contribution to geoidal heights. Aust. J. Geod. Photo. Surv., 42, 75-98.

Kearsley, A. H. W., 1986: The determination of precise geoid height differences using ring integration. Bollettino di Geodesia e Scienze Affini, 45, 151-174.

Kearsley, A. H. W., 1988a: Tests on the recovery of precise geoid height differences from gravimetry. J. Geophys. Res., 93, 6559-6570, doi: 10.1029/JB093iB06p06559. [Link]

Kearsley, A.H.W., 1988b: The determination of the geoid ellipsoid separation for GPS levelling. Australian Surveyor, 34, 11-18, doi: 10.1080/00050326.1988.10438999. [Link]

Kearsley, A. H. W. and R. Govind, 1991: Geiod evaluation in Australia-A status report. Australian Surveyor, 36, 30-40, doi: 10.1080/00050326.1991.10438710. [Link]

Kearsley, A. H. W. and R. Govind, 1992: Geoid evaluation in Australia status and problems. In: Rapp, R. H. and F. Sansò (Eds.), Determination of the Geoid, International Association of Geodesy Symposia, Vol. 106, Springer, New York, NY, 251-260, doi: 10.1007/978-
1-4612-3104-2_30. [Link]

Kearsley, A. H. W . and J. Steed, 1995: AUSGeoid93. International Geoid Service Bulletin, 2, 1-6.

Kearsley, A. H. W., G. J. Rush, and P. W. O'Donnell, 1988: The Australian height datum problems and proposals. Australian Surveyor, 34, 363-380, doi: 10.1080/00050326.1988.10438540. [Link]

Kearsley, A. H. W., R. Forsberg, A. Olesen, L. Bastos, K. Hehl, U. Meyer, and A. Gidskehaug, 1998: Airborne gravimetry used in precise geoid computations by ring integration. J. Geod., 72, 600-605, doi: 10.1007/ s001900050198. [Link]

Kirby, J. F. and W. E. Featherstone, 1999: Terrain correcting Australian gravity observations using the national digital elevation model and the fast Fourier transform. Aust. J. Earth Sci., 46, 555-562, doi: 10.1046/j.14400952.1999.00731.x. [Link]

Kirby, J. F. and W. E. Featherstone, 2001: Anomalously large gradients in Version 1 of the "GEODATA 9 SECOND" Digital Elevation Model of Australia, and their effects on gravimetric terrain corrections. Cartography, 30, 1-10, doi: 10.1080/00690805.2001.9714131. [Link]

Kirby, J. F., W. E. Featherstone, and A. H. W. Kearsley, 1997: Geoid computations using ring integration: Gridded versus point data. Geomatics Research Australasia, 67, 33-45.

Lemoine, F. G., S. C. Kenyon, J. K. Factor, R. G. Trimmer, N. K. Pavlis, D. S. Chinn, C. M. Cox, S. M. Klosko, S. B. Luthcke, M. H. Torrence, Y. M. Wang, R. G. Williamson, E. C. Pavlis, R. H. Rapp, and T. R. Olson, 1998: The development of the joint NASA GSFC and the National Imagery and Mapping Agency (NIMA) geopotential model EGM96. Report NASA/TP-1998206861, National Aeronautics and Space Administration, Goddard Space Flight Center, Greenbelt, Maryland, USA.

Mather, R. S., 1969: The free air geoid for Australia. Geophys. J. Int., 18, 499-516, doi: 10.1111/j.1365246X.1969.tb03374.x. [Link]

Mather,R.S., 1971: The geocentric orientation vector for the Australian Geodetic Datum. Geophys. J.Int., 22, 55-81, doi: 10.1111/j.1365-246X.1971.tb03583.x. [Link]

McCubbine, J. C., W.E. Featherstone, and J. F. Kirby, 2017: Fast-Fourier-based error propagation for the gravimetric terrain correction. Geophysics, 82, G71-G76, doi: 10.1190/GEO2016-0627.1. [Link]

McCubbine, J. C., W. E. Featherstone, and N. J. Brown, 2019: Error propagation for the Molodensky $G_{1}$ term. J. Geod., 93, 889-898, doi: 10.1007/s00190-018-12116. [Link]

Meissl, P., 1971: Preparations for the numerical evaluation of second order Molodensky-type formulas. Reports of Department of Geodetic Science, Report No. 163, 
Department of Geodetic Science, The Ohio State University Research Foundation, Columbus, Ohio, USA.

Merry, C. L., 2003: DEM-induced errors in developing a quasi-geoid model for Africa. J. Geod., 77, 537-542, doi: 10.1007/s00190-003-0353-2. [Link]

Molodensky, M. S., V. F. Yeremeev, and M. I. Yurkina, 1960: Methods for Study of the External Gravitational Field and Figure of the Earth. TRUDY Ts NIIGAiK 131, Geodezizdat, Moscow (English translation: Israel Program for Scientific Translation, Jerusalem 1962).

Molodensky, M. S., V. F. Yeremeyev, and M. I. Yurkina, 1962: An evaluation of accuracy of Stokes' series and of some attempts to improve his theory. Bull. Géodésique, 63, 19-37, doi: 10.1007/BF02528170. [Link]

Morgan, P., 1992: An analysis of the Australian Height Datum: 1971. Australian Surveyor, 37, 46-63, doi: 10.1080/00050326.1992.10438774. [Link]

Moritz, H., 1968: On the use of the terrain correction in solving Molodensky's problem. Reports of Department of Geodetic Science, Report No. 108, Department of Geodetic Science, The Ohio State University Research Foundation, Columbus, Ohio, USA.

Moritz, H., 1980: Geodetic reference system 1980. Bull. Géodésique, 54, 395-405, doi: 10.1007/BF02521480. [Link]

Pavlis, N. K., S. A. Holmes, S. C. Kenyon, and J. K. Factor, 2012: The development and evaluation of the Earth Gravitational Model 2008 (EGM2008). J. Geophys. Res., 117, B04406, doi: 10.1029/2011JB008916. [Link]

Pavlis, N. K., S. A. Holmes, S. C. Kenyon, and J. K. Factor, 2013: Correction to "The development and evaluation of the Earth Gravitational Model 2008 (EGM2008)". J. Geophys. Res., 118, 2633-2633, doi: 10.1002/ jgrb.50167. [Link]

Rapp, R. H., 1961: The orthometric height. Master Thesis, Department of Geodetic Science, Ohio State University, Columbus, USA.

Rapp, R. H., 1975: Effect of certain anomaly correction terms on potential coefficient determinations of the Earth's gravitational field. Bull. Géodésique, 115, 5763, doi: 10.1007/BF02523943. [Link]

Rapp, R. H. and N. K. Pavlis, 1990: The development and analysis of geopotential coefficient models to spherical harmonic degree 360. J. Geophys. Res., 95, 2185521911, doi: 10.1029/JB095iB13p21885. [Link]

Rapp, R. H., Y. M. Wang, and N. K. Pavlis, 1991: The Ohio State 1991 geopotential and sea surface topography harmonic coefficient models. Report No. 410, Department of Geodetic Science and Surveying, The Ohio State University, Columbus, Ohio, USA, 94 pp.

Rizos, C., R. Coleman, and N. Ananga, 1991: The Bass Strait GPS survey: Preliminary results of an experiment to connect Australian height datums. Aust. J.
Geod. Photo. Surv., 55, 1-25.

Roelse, A., H. W. Granger, and J. W. Graham, 1971: The adjustment of the Australian levelling survey 19701971. Technical Report 12, Division of National Mapping, Canberra, Australia.

Sandwell, D., E. Garcia, K. Soofi, P. Wessel, M. Chandler, W. H. F. Smith, 2013: Toward 1-mGal accuracy in global marine gravity from CryoSat-2, Envisat, and Jason-1. The Leading Edge, 32, 892-899, doi: 10.1190/ tle32080892.1. [Link]

Sandwell, D. T., R. D. Müller, W. H. F. Smith, E. Garcia, and R. Francis, 2014: New global marine gravity model from CryoSat-2 and Jason-1 reveals buried tectonic structure. Science, 346, 65-67, doi: 10.1126/science.1258213. [Link]

Schack, P., C. Hirt, M. Hauk, W. E. Featherstone, T. J. Lyon, and S. Guillaume, 2018: A high-precision digital astrogeodetic traverse in an area of steep geoid gradients close to the coast of Perth, Western Australia. J. Geod., 92, 1143-1153, doi: 10.1007/s00190-0171107-x. [Link]

Smith, W. H. F. and P. Wessel, 1990: Gridding with continuous curvature splines in tension. Geophysics, 55, 293-305, doi: 10.1190/1.1442837. [Link]

Soltanpour, A., H. Nahavandchi, and W. E. Featherstone, 2006: The use of second-generation wavelets to combine a gravimetric quasigeoid model with GPS-levelling data. J. Geod., 80, 82-93, doi: 10.1007/s00190006-0033-0. [Link]

Stead, J. and S. Holtznagel, 1994: AHD heights from GPS using AUSGeoid93. Australian Surveyor, 39, 21-27, doi: 10.1080/00050326.1994.10558404. [Link]

Vaníček, P. and W. E. Featherstone, 1998: Performance of three types of Stokes's kernel in the combined solution for the geoid. J. Geod., 72, 684-697, doi: 10.1007/ s001900050209. [Link]

Vaníček, P. and A. Kleusberg, 1987: The Canadian geoid - Stokesian approach. manuscripta geodeatica, 12, 8698.

Vaníček, P. and L. E. Sjöberg, 1991: Reformulation of Stokes's theory for higher than second-degree reference field and modification of integration kernels. J. Geophys. Res., 96, 6529-6539, doi: 10.1029/90JB02782. [Link]

Vella, J. P. and W. E. Featherstone, 1999: A gravimetric geoid model of Tasmania, computed using the onedimensional fast Fourier transform and a deterministically modified kernel. Geomatics Research Australasia, 70, 53-76.

Wessel, P., W. H. F. Smith, R. Scharroo, J. Luis, and F. Wobbe, 2013: Generic mapping tools: Improved version released. Eos Trans. AGU, 94, 409-410, doi: 10.1002/2013EO450001. [Link]

Wichiencharoen, C., 1982: The indirect effects on the 
computation of geoid undulations. Report No. 336, Department of Geodetic Science, The Ohio State University, Columbus, Ohio, USA.

Wong, L. and R. Gore, 1969: Accuracy of geoid heights from modified Stokes kernels. Geophys. J. Int., 18, 8191, doi: 10.1111/j.1365-246X.1969.tb00264.x. [Link]

Wu, Y., A. Abulaitijiang, W. E. Featherstone, J. C. McCubbine, and O. B. Andersen, 2019: Coastal gravity field refinement by combining airborne and ground-based data. J. Geod., 93, 2569-2584, doi: 10.1007/s00190-
019-01320-3. [Link]

Zhang, K., 1997: An evaluation of FFT geoid determination techniques and their application to Australian GPS heighting. Ph.D. Thesis, Curtin University of Technology, Australia.

Zhang, K. and W. E. Featherstone, 2004: Investigation of the roughness of the Australian gravity field using statistical, graphical, fractal and Fourier power spectrum techniques. Surv. Rev., 37, 520-530, doi: 10.1179/ sre.2004.37.293.520. [Link] 